\title{
Additive Manufacturing: Making Imagination the Major Limitation
}

\author{
YUWEI ZHAI, ${ }^{1,3}$ DIANA A. LADOS, ${ }^{1,4}$ and JANE L. LAGOY ${ }^{2,5}$ \\ 1.--Integrative Materials Design Center (iMdc), Worcester Polytechnic Institute, 100 Institute \\ Road, Worcester, MA 01609, USA. 2.-Bodycote IMT, Inc., 155 River Street, Andover, MA 01810, \\ USA. 3.-e-mail: yzhai@wpi.edu. 4.-e-mail: lados@wpi.edu. 5.—e-mail: jane.lagoy@bodycote. \\ com
}

\begin{abstract}
Additive manufacturing (AM) refers to an advanced technology used for the fabrication of three-dimensional near-net-shaped functional components directly from computer models, using unit materials. The fundamentals and working principle of AM offer several advantages, including near-net-shape capabilities, superior design and geometrical flexibility, innovative multimaterial fabrication, reduced tooling and fixturing, shorter cycle time for design and manufacturing, instant local production at a global scale, and material, energy, and cost efficiency. Well suiting the requests of modern manufacturing climate, AM is viewed as the new industrial revolution, making its way into a continuously increasing number of industries, such as aerospace, defense, automotive, medical, architecture, art, jewelry, and food. This overview was created to relate the historical evolution of the AM technology to its state-of-the-art developments and emerging applications. Generic thoughts on the microstructural characteristics, properties, and performance of AM-fabricated materials will also be discussed, primarily related to metallic materials. This write-up will introduce the general reader to specifics of the $\mathrm{AM}$ field vis-à-vis advantages and common techniques, materials and properties, current applications, and future opportunities.
\end{abstract}

\section{INTRODUCTION}

Following the contour drawn by science fiction, the rapid development of modern technologies is turning fantasy into reality, challenging both science fiction writers and engineers to push their imaginations further. Additive manufacturing (AM) technology, or three-dimensional (3D) printing, is a key enabler of this transformation.

AM refers to a broad family of techniques that turn 3D digital designs into actual functional parts in the same way an office printer places twodimensional (2D) digital files onto pieces of paper. ASTM F2792 defines AM as "a process of joining materials to make objects from 3D model data, usually layer upon layer, as opposed to subtractive manufacturing methodologies." ${ }^{\text {ASTM }}$ also specifies other commonly used synonyms for AM including additive fabrication, additive processes, additive techniques, additive layer manufacturing, layer manufacturing, and freeform fabrication. The general working principle of AM is schematically represented in Fig. 1.2 A 3D solid computer aided design (CAD) model is first sliced into layers to generate digital information based on the geometry of each layer. This digital information then becomes the tool path used to selectively combine unit materials, typically sheets, wires, and powders layer by layer into final (near) net-shape objects.

This working principle offers AM technology superior flexibility. Complex shapes, such as internal cooling channels that cannot be achieved by machining, can be readily created by selectively placing material only where is needed. The digital models are not only freeform, but also can be shared all over the world, which makes possible instant local production on a global scale. ${ }^{3}$ In addition, AM technology does not require molds, fixtures, or tooling, which effectively reduces the long lead time caused by mold and/or tool design and manufacturing. Near-net shaping is another important feature of AM technology, which significantly 


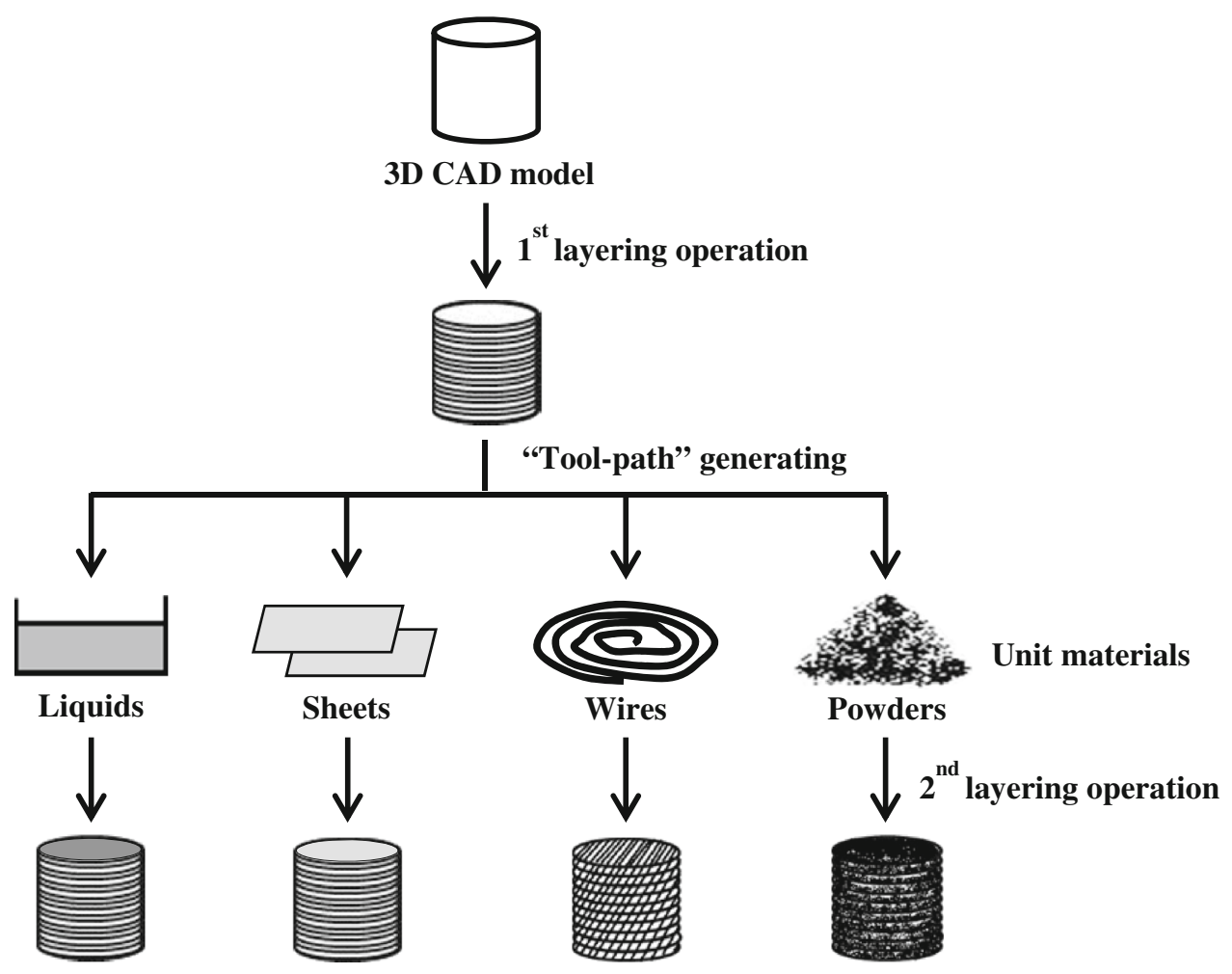

Fig. 1. Schematic representation of the working principle of AM: steps in the layer-wise fabrication of a product using different unit materials. ${ }^{2}$

minimizes material use and waste. A joint study by European Aeronautic Defence and Space Company (EADS, Bristol, UK) Innovation Works (IW) and EOS Innovation Center, Warwick, UK has shown that $\mathrm{AM}$ is able to reduce the consumption of raw materials by up to $75 \%{ }^{4}$ These combined characteristics give AM great potential for energy and cost savings as well as reducing the overall carbon footprint compared to conventional manufacturing technologies such as subtractive machining, casting, forging, and powder metallurgy. For instance, a statistical analysis was performed to compare AM technology (the MESO-CLAD process; MesoCoat, Inc., Euclid, $\mathrm{OH}$ ) with conventional machining according to their cumulative impacts on resources, ecosystem quality, and human health, considering the effects of raw material extraction, powder production, transportation, component manufacturing, and recycling. The results have indicated that AM has a 70\% lower total environmental impact than conventional machining. ${ }^{5}$ Regarding cost benefits, a different study has recently projected that more than $\$ 2.5$ million savings in fuel costs per year can be achieved through $50-80 \%$ weight reduction of metal brackets in an aircraft using AM technology. ${ }^{6}$ GE has also achieved up to $25 \%$ reduction in production time and cost savings, without sacrificing performance, using additive technologies on an industrial scale. ${ }^{7}$

Given the current manufacturing climate and increasing role played by AM, this write-up was developed to relate the historical perspective and evolution of this technology to state-of-the-art developments and emerging applications. The microstructure, properties, and performance of additive manufactured materials will also be generically discussed, especially as they pertain to the fastest growing arm of this technology-the fabrication of metallic materials.

\section{HISTORY AND EVOLUTION OF AM}

While being considered an up-and-coming technology with an annual growth rate of $26 \%$ for the past 20 years, ${ }^{8}$ the roots of AM go back 150 years to the fields of photo-sculpture and topography. The history and evolution of AM technology were comprehensively discussed by Bourell et al., ${ }^{9}$ and a brief summary is given here.

In 1860, French artist François Willème created $3 \mathrm{D}$ replicas of a subject by arranging it on a platform surrounded by 24 cameras, which recorded the profile of the subject every $15^{\circ}$. Then, 24 cylindrical portions of the subject were carved accordingly and arranged together into a 3D photograph. Thirty years later, Blanther ${ }^{10}$ developed another layering method for making topographical relief maps. By tracing contour patterns on a series of wax plates and stacking the generated wax sections, both positive and negative surfaces were created and used as the mold for making paper relief maps.

Modern AM technology, symbolized by stereolithography (SL), found its origin in a system proposed by Munz ${ }^{11}$ in 1951. In Munz's system, a layer 
of transparent photopolymer was selectively exposed and hardened according to the cross-section of a scanned object using a piston mechanism. In 1968, Swainson ${ }^{12}$ proposed the use of laser beam to solidify photosensitive polymers; parallel and similar work was also conducted at Battelle Laboratories. ${ }^{13}$ Ciraud $^{14}$ was the first to introduce in 1971 the use of powders, which were partially melted, using laser, electron or plasma beams as heat sources. In 1981, Housholder ${ }^{15}$ described the earliest "powder laser sintering" process without having it commercialized. At about the same time, Kodama $^{16}$ from Nagoya Municipal Industrial Research Institute published the first rapid prototyping system, using functional photopolymer materials, while Herbert ${ }^{17}$ from $3 \mathrm{M}$ (St. Paul, MN) developed the earliest SL system that used a computer to command the ultraviolet laser beams.

AM technology has evolved significantly over the past three decades, facilitating the launching of many AM companies. 3D Systems (Rock Hill, SC) was founded in 1986 by Charles Hull to commercialize the SL technique. The selective laser sintering (SLS) method was developed at approximately the same time and led to the formation of DTM, which was acquired by $3 \mathrm{D}$ Systems in 2001 . $^{18}$ Stratasys (Eden Prairie, MN) was founded in the $1990 \mathrm{~s}$, with the commercialization of the fused deposition modeling process. The freeform fabrication of metallic objects then garnered major attention, and many methodologies, including direct metal laser sintering (DMLS), laser-engineered net shaping (LENS), electron-beam melting (EBM), and others were developed specifically for metals such as stainless steel, titanium, and nickel-base alloys. A classification of AM techniques is provided in the Appendix (Table I), together with a list of common AM techniques, manufacturers, and equipment vendors (Table II). A few techniques for fabricating metallic materials are highlighted in the following section.

\section{DISCUSSION OF SELECTED METAL AM TECHNIQUES AND THEIR OPERATING PRINCIPLES}

Although it started from organic materials, AM technology found a special place in the manufacturing of metallic materials by meeting the requirements for performance, enhanced manufacturing efficiency, sustainability, and energy and cost savings. Numerous AM techniques have been developed to capitalize on these important benefits, as detailed in the Appendix. Several of these techniques have been either developed specifically or adapted from polymer-based methods for the fabrication of metallic components. A classification of metal AM techniques based on heat source and material feedstock is concisely presented here, together with basic operating principles of selected processes in each class.

\section{Powder Bed Fusion (Laser Beam/Electron Beam/Inkjet Head+Powder Bed System)}

Powder bed fusion technology started from SLS and has evolved into various techniques that have similar working principles but use different binding mechanisms. Typical methods based on the combination of laser beams and powder beds include the original SLS owned by 3D Systems and the widely used DMLS from EOS. A similar technique known as LaserCUSING was trademarked by Concept Laser (Lichtenfels, Germany), which also produces their own series of machines. ${ }^{19}$ Substituting laser beams with electron beams yields the EBM technique developed by Arcam AB (Mölndal, Sweden). If an inkjet head and a powder bed system are combined, the process is referred to as $3 \mathrm{D}$ printing, ${ }^{*}$ a process developed at MIT and licensed to ZCorp (Rock Hill, SC) in 1995. As an example, the working principle of DMLS is schematically represented in Fig. 2.

The whole process assembly consists of a laser scanning system, a powder delivery piston, a roller, and a fabrication piston. Before fabrication starts, the powder delivery piston moves up and the fabrication piston moves down one layer thickness. The powder is spread and lightly compacted by the roller over the surface of the fabrication piston, and a laser beam is then driven over it to selectively melt the powder under the guidance of the scanner system. After each layer is completed, the fabrication piston moves down another layer thickness and a new layer of powder is spread over. This process continues until the whole part is created. Upon finishing, the fabrication piston rises up and elevates the final object; excess powder is brushed away and partially reused after proper treatments. ${ }^{20}$ One of the advantages of the powder bed fusion systems is that support structures are not required. However, supports are often added to provide thermal pathways for heat dissipation and better geometry control.

\section{Direct Energy Deposition: Powder-Based Methods (Laser Beam+Powder Delivery Nozzle)}

In this class, powder bed systems are replaced by powder delivery nozzles. There are two major techniques in this group: (I) LENS, developed at Sandia National Laboratories in the 1990s and licensed to Optomec in 1997 (who has been the sole manufacturer and distributor of LENS systems since then ${ }^{21}$ ) and (II) direct metal deposition (DMD) provided by POM Group (Auburn Hills, MI). The main differences between the two processes consist in the details of machine control and implementation; ${ }^{22}$ DMD also allows processing in open atmosphere

\footnotetext{
*The term 3D printing (3DP) here refers to the specific technique that was developed at MIT (Cambridge, MA). The term 3DP is also commonly used as a synonym for additive manufacturing.
} 


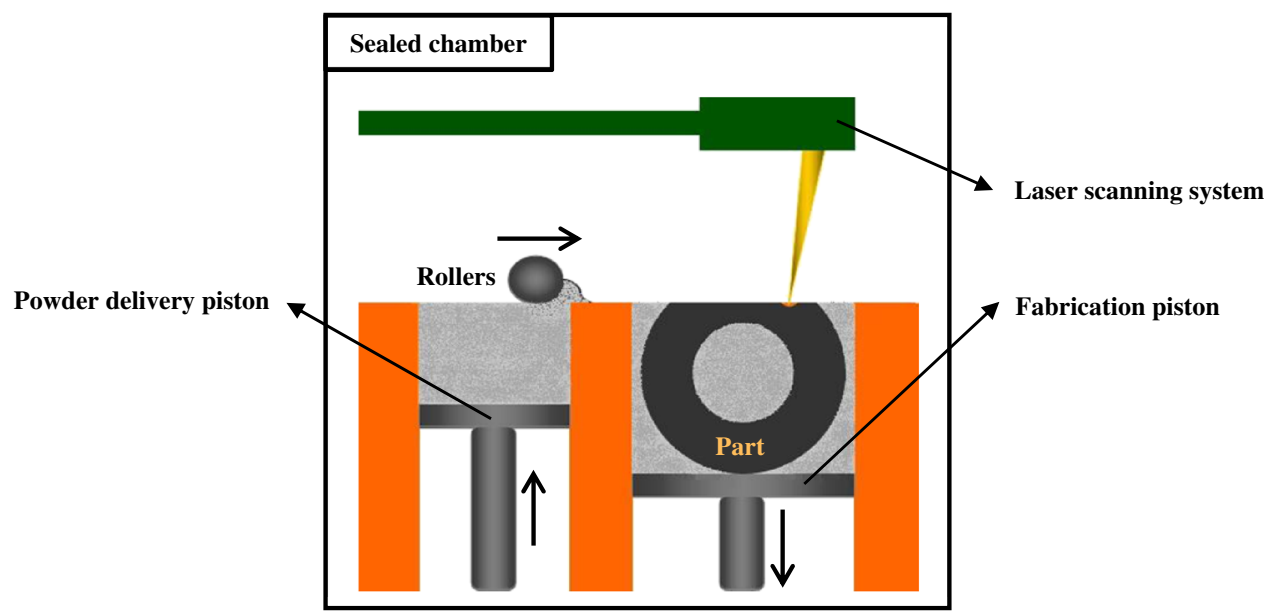

Fig. 2. Schematic representation of DMLS system. ${ }^{2}$

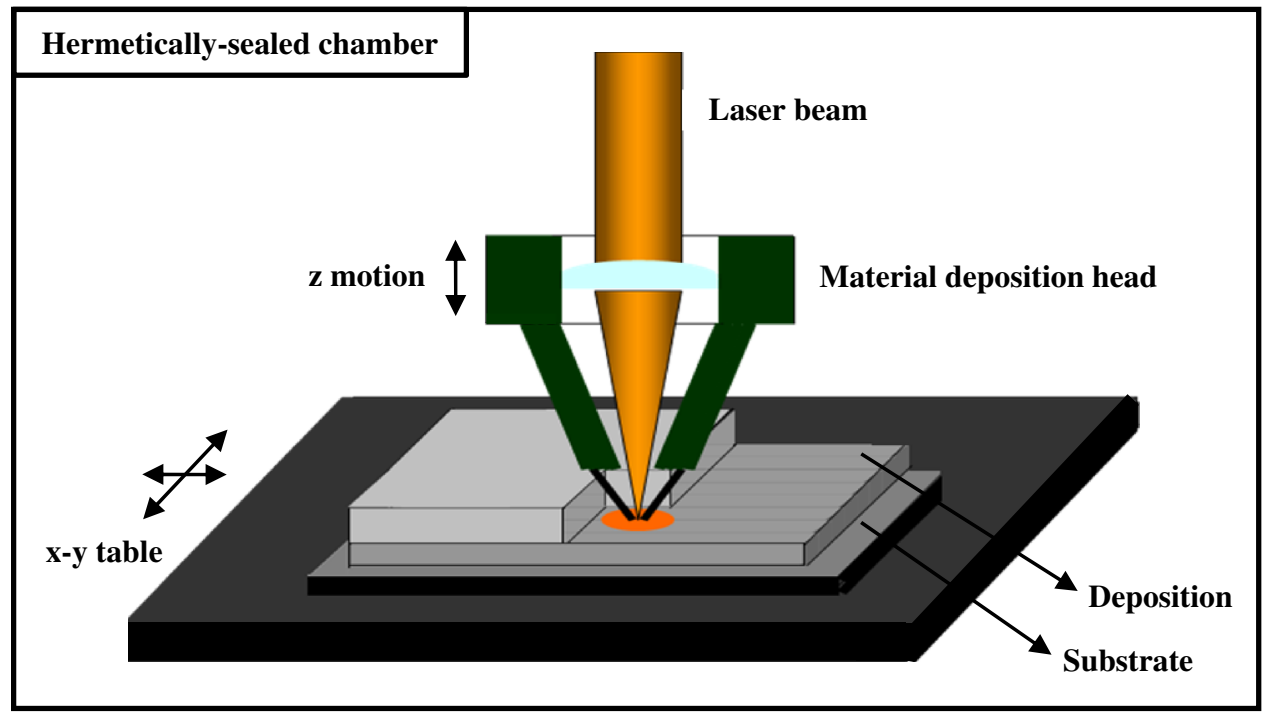

Fig. 3. Schematic representation of LENS process. $^{2}$

using local shielding of the molten metal. The LENS technique, for example, can process a wide range of metals, including titanium, nickel-base superalloys, and stainless and tool steels, which are all commercially available in powder form as required for this process. ${ }^{23} \mathrm{~A}$ schematic representation of the LENS process is shown in Fig. 3.

A substrate is first placed onto the $x-y$ motion table. Then, a high-power focused laser beam creates a melting pool on the substrate to which metal powders are delivered coaxially. A metal powderlaser beam interaction zone is created to fuse the metal powders into a deposit. Typically, the $x-y$ motion table moves in a raster manner to fabricate each layer of the object according to the CAD design, and the powder delivery nozzle moves upward upon completing each layer to start the deposition of a new layer. Metal powders are typically delivered and distributed using an inert carrier gas to shield the molten metal pool from oxidation and to promote layer-to-layer adhesion by providing better surface wetting. ${ }^{24}$

\section{Direct Energy Deposition: Wire-Based Meth- ods (Electron Beam+Metal Wire Feedstock)}

Direct energy deposition includes another class of metal AM techniques, which use solid wire feedstock instead of powders. Electron beam freeform fabrication (EBF3) is one of the main techniques belonging to this class. EBF3 was developed by Lockheed Martin (Bethesda, MD) in 1999 and disclosed in $2002 .^{25}$ This technology was extensively studied and improved at NASA Langley Research Center (Hampton, VA) for producing unitized structures using aerospace materials such as 


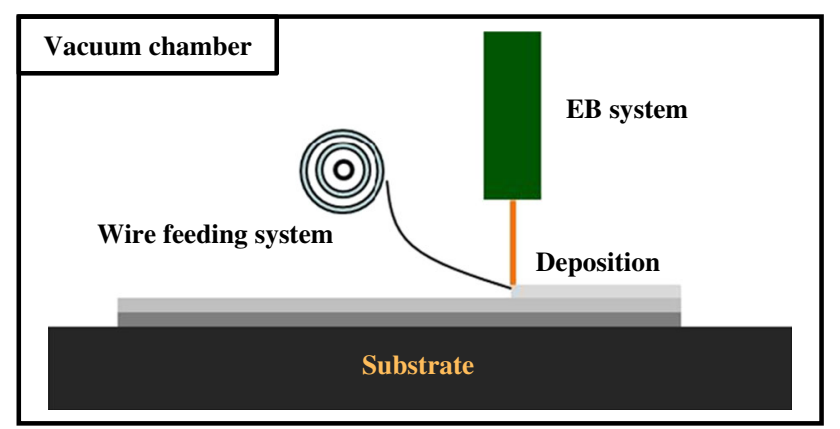

Fig. 4. Schematic representation of EBF3 system. ${ }^{2}$

aluminum, titanium, nickel-base alloys, titanium aluminides, metal matrix composites, and highstrength steels. ${ }^{26}$ The EBF3 technique operates in a similar fashion to LENS except that electron beams are used as the heat source. EBF3 process is performed under a vacuum environment $\left(10^{-4}\right.$ torr or lower), and a metal wire feeding system is incorporated to deliver feedstock to the molten pool offaxially. The electron beam can be controlled and deflected very precisely and couples very effectively with highly reflective materials. This process has an efficiency of nearly $100 \%$ in wire consumption and $95 \%$ in power usage ${ }^{26} \mathrm{~A}$ schematic representation of the EBF3 system is shown in Fig. 4.

NASA Langley Research Center has two types of EBF3 systems-ground based and portable. The ground-based system has a dual-wire feeding system, which can be loaded with either fine or coarse wires for different feature definitions, or with two different alloys to produce compositional gradients or multimaterial components. The portable system has a single-wire feeder, which can be used for finer metal wire and has higher positioning precision compared to the ground-based system. These features make it ideal for the fabrication of smaller parts with intricate details. ${ }^{26}$ NASA has two portable EBF3 machines, one that has successfully flown on the microgravity research airplane and another that is being developed for potential in-space manufacturing activities.

\section{EXAMPLES OF AM APPLICATIONS AND SUSTAINABILITY CONSIDERATIONS}

The use of AM continues to expand as more advanced AM techniques are being developed and improved. One of the earliest applications of AM technology was the production of tools with special cooling channels for plastic injection molding. Today, AM technology is employed to make a variety of products, including medical implants; orthopedic and dental parts; hearing aids; forming tools; aerospace, military, and automotive components; electronics; video game avatars; art; jewelry; commercial lighting; three-dimensional textiles; food; and more. Current research is even delving into biomedical applications with the utilization of $\mathrm{AM}$ in living tissue generation.

As an example of the U.S. AM industry, the company Directed Manufacturing Inc. (DMI; Austin, TX) depends heavily on the aerospace and medical markets. DMI spun off from an R\&D/prototyping venture in 2006 to commercialize the production use of AM. Currently at 10 AM machines, DMI plans to add one or two machines annually for the foreseeable future as many customers have converted to AM from castings, forgings, multicomponent assembling, or subtractive manufacturing (machining). Although some secondary machining is often required for production parts, for complex part geometries, AM is considerably faster and more economical compared with other manufacturing methods. ${ }^{27}$

In the medical sector, AM is seen to have great ability to produce precise medical devices, such as surgical instruments ${ }^{28}$ and customized implants, including partial skull plates and joint replacements. ${ }^{29}$ It has also been successfully applied in the prosthetic industry to design and fabricate lightweight and low-cost robotic parts, such as hands and wrists, thus consolidating complex assemblies into single parts. ${ }^{30}$ The military is also interested in AM's portability and adaptive capabilities for multiple in-field uses. Additional applications include unmanned aerial vehicles, the next generation of Mars rovers, commercial airplane wing brackets and cooling ducts, turbine engine blades, heat exchangers, and the repair of blades and dies. ${ }^{31-33}$ To realize its full potential, however, AM still needs to overcome the long and expensive process of getting qualifications, especially in the aerospace, military, and medical fields, which are the target markets for high-dollar components and demanding structural applications. ${ }^{26}$

For a specific automotive application, Daimler AG (Stuttgart, Germany) has partnered with Concept Laser and Fraunhofer Institute of Laser Technology to replace costly and time-consuming sand and die casting processes used to make large metal functional components with AM fabrication methods for weight-optimized geometries. ${ }^{34}$ In an interesting twist, the competing process of investment casting is looking to AM for streamlining their process of developing molds, including decreasing cost by reducing waste and eliminating tooling, increasing achievable complexity, and accelerating prototype development and production planning. ${ }^{35}$

In the jewelry field, precious metal designs bring some unique challenges compared with more common AM alloys because of the high-polished surfaces desired by customers. Whereas cast jewelry actually requires less finishing, AM allows the creation of designs never before achievable, giving artists and designers a new level of geometrical detail never before seen. ${ }^{36}$ Similarly, art or any industry needing to recreate legacy components no longer available now has the opportunity to image a 
piece, enter the data into an AM machine, and build it anew.

In 2009, the Roadmap for Additive Manufacturing (RAM) Workshop was held in Washington, DC, where topics related to research needs and developing trends were discussed by 65 invited experts. Energy and sustainability represented an important chapter in the workshop report, foreseeing AM's positive impact on sustainability but lacking concrete and complete sustainability assessments. ${ }^{37,38}$ In 2010, Sreenivasan et al. ${ }^{38}$ performed an overall energy assessment for SLS of polymers, using eco-indicators. The results have shown an energy consumption distribution with approximately 16\% coming from the laser systems, 25\% from feed and build piston, and $40 \%$ from powder feed and partbed heaters. Better thermal management, elimination of powder heating, and adoption of high-efficiency lasers were identified as potential methods for reducing energy consumption. Such systematic energy and sustainability assessments need to be done for other AM techniques and applications, including those relevant to metallic materials, to quantify their environmental advantages and open new opportunities and markets.

\section{PROPERTIES AND PERFORMANCE OF ADDITIVE MANUFACTURED MATERIALS}

Above and beyond cost, energy, and sustainability advantages, the properties and performance of AM products are essential factors in evaluating the suitability of this technology, especially for critical applications, including aerospace, ground transportation, and medical. In light of this fact, EWI organized the first U.S. Additive Manufacturing Consortium (AMC) in 2010 with 27 members including industry, government agencies, nonprofit research organizations, and universities to accelerate innovation. They identified five key topics for improvement: (I) material property databases, (II) process model compensation for distortion/first time accuracy, (III) process sensing and control and nondestructive evaluation, (IV) clear and affordable paths to certification and qualification, and (V) bigger, faster, and more capable OEM equipment. ${ }^{39}$ Substantial financial investments have also been made to support such endeavors, most recently by the inception of NAMII (National Additive Manufacturing Innovation Institute), funded by the U.S. Department of Commerce (DOC), Department of Defense (DOD), Department of Energy (DOE), National Science Foundation (NSF), and NASA, along with multiple industrial, academic, and nonprofit partners.

Given that properties and performance are greatly influenced by the materials' internal characteristics, a fundamental understanding of the microstructure evolution in different AM techniques is imperative. Extensive research has been conducted on various additive manufactured metallic materials, $, 2,40$ and dramatically different microstructures were observed compared to conventionally manufactured materials.
These include distinct layer patterns and heat-affected zones, directional grains, and typically very fine characteristic features inside the grains.

In LENS fabricated Ti-6Al-4V alloys, ${ }^{2}$ for example, large columnar grains parallel to the deposition direction were observed as a result of heat extraction from the substrate, as shown in Fig. 5a-e. Macroheat-affected zones (macro-HAZs) were found at the interfaces between LENS depositions and substrates as illustrated in Fig. $5 \mathrm{~d}$ and e. In addition and specific to AM, micro-heat-affected zones ( $\mu \mathrm{HAZs}$ ) with coarser characteristic features were also observed between layers due to reheating of previous layers upon subsequent depositions. ${ }^{2}$ These $\mu$ HAZs give AM microstructures their distinct "layered" appearance as seen in Fig. 5a-c. Directional grains, macro-HAZ, and $\mu \mathrm{HAZ}$ yield nonuniform microstructures in AM materials, leading to property differences in various orientations. $^{2,41-44}$

The internal microstructural characteristics of AM-fabricated metals, as well as their surface conditions, are affected by processing parameters. Thinner layers, finer columnar grains, smaller porosity, and narrower macro-HAZs and $\mu \mathrm{HAZs}$ were observed in LENS Ti-6Al-4V fabricated using low power (Fig. 5a, b, and d), versus high power (Fig. 5c and e). ${ }^{2}$ Low-power LENS fabrication also creates a better surface finish (Fig. 6a and b), than high-power fabrication (Fig. 6c and d), at the expense of slower manufacturing speed. ${ }^{2}$ The type of heat source is another factor that influences the microstructure and properties of AM-fabricated materials. ${ }^{45}$

Compared with parts made by conventional manufacturing processes, AM-fabricated components show promising properties for most metallic materials. ${ }^{2,46-48}$ However, the presence of shrinkage porosity and residual stress can affect their static and dynamic properties depending on the applied AM technique and processing parameters. Thus, post-AM processing is another important direction of investigation. Hot isostatic pressing and heat treatments are considered effective methods for eliminating porosity, relieving residual stress, and recovering ductility. However, as a result of specific processing conditions and hence characteristic microstructures, conventional postprocessing treatments may not always lead to the expected properties and behavior of the AM-fabricated materials. ${ }^{49}$ Moreover, when AM technology is applied for laser cladding and repairing damaged or improperly manufactured components, post-AM heat treatments are impractical because of the need to preserve base/ substrate material properties. Therefore, achieving the desired properties and performance of the materials and components requires judicious selection of the AM process, as well as tailoring of the fabrication conditions, postprocessing conditions, and parameters.

\section{FUTURE AND DEVELOPING TRENDS IN AM}

Offering the advantages of fast and precise manufacturing as well as positive environmental 


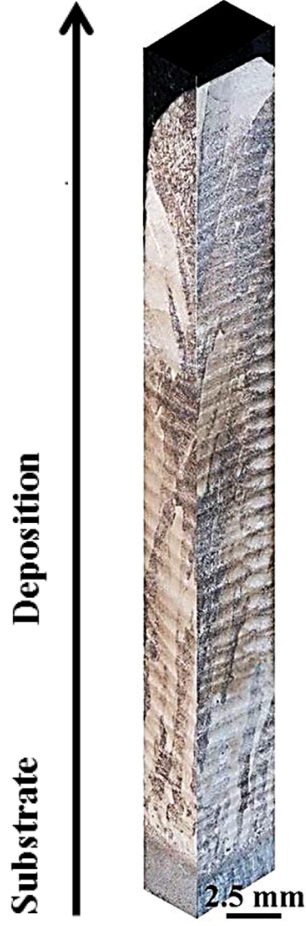

(a)

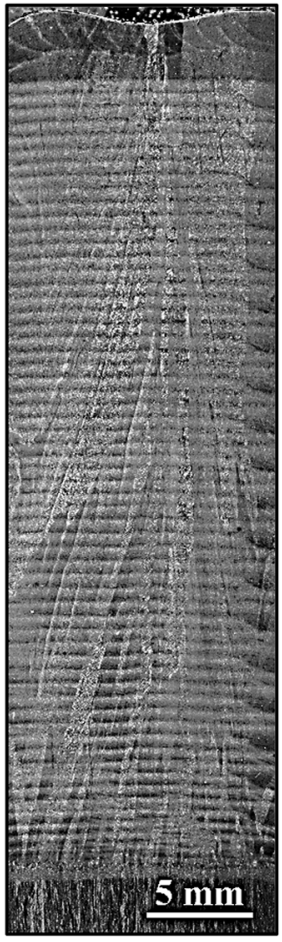

(b)

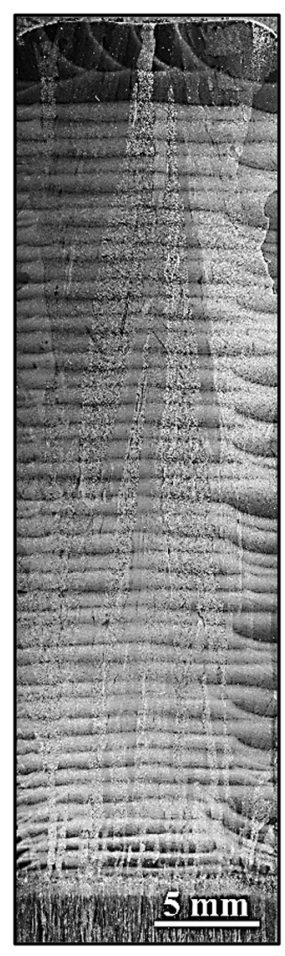

(c)

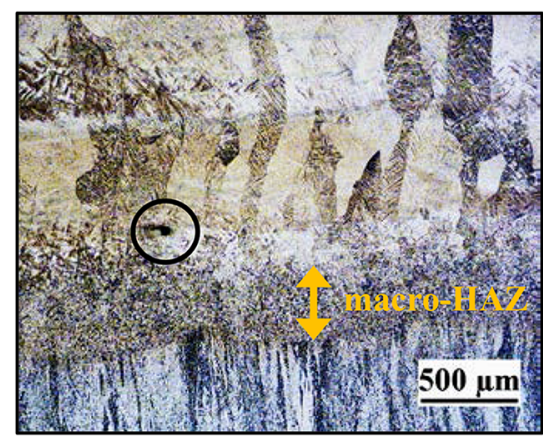

(d)

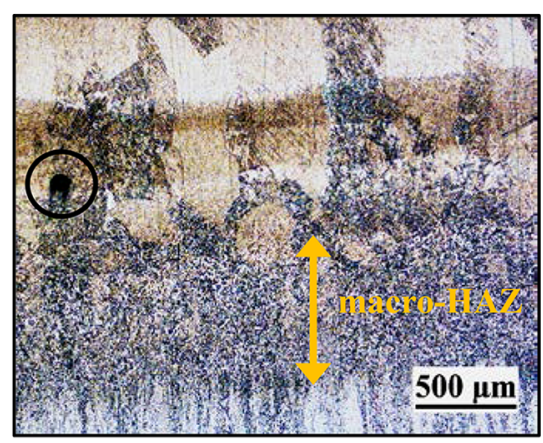

(e)

Fig. 5. Layered microstructures of as-deposited LENS Ti-6Al-4V fabricated using different laser powers: (a, b, d) 330 W and (c, e) 780 W-lower power fabrication features thinner layers, finer columnar grains, smaller porosity (circled), and narrower macro-HAZ and $\mu \mathrm{HAZ}$. (a) represents a 3D panoramic view of the low power AM deposition on a mill-annealed substrate. ${ }^{2}$

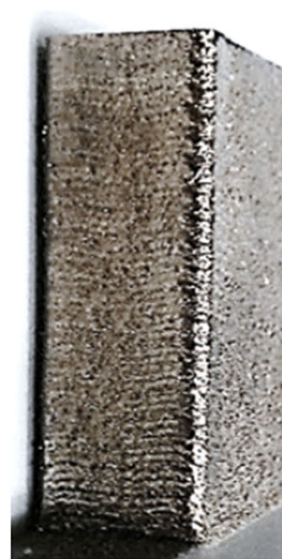

(a)

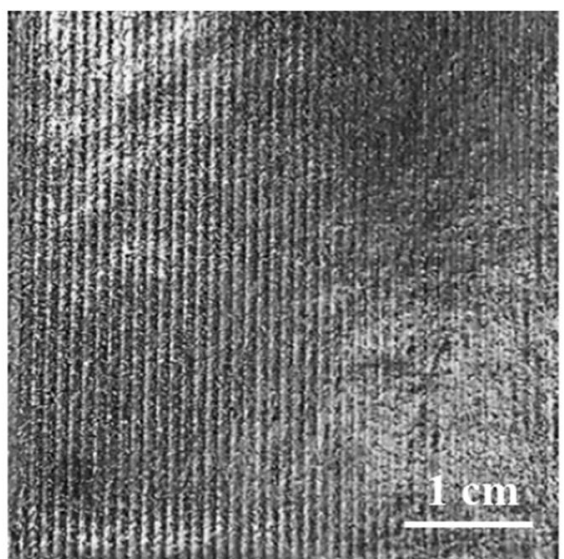

(b)

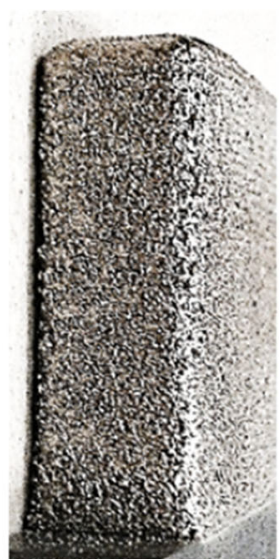

(c)

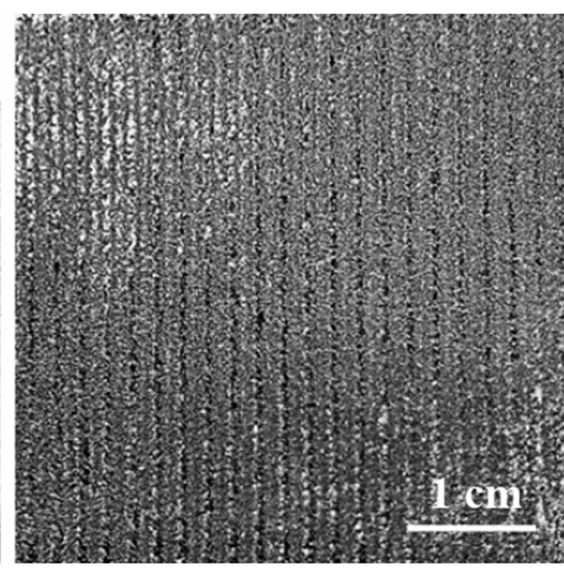

(d)

Fig. 6. Surface photographs of LENS Ti-6Al-4V fabricated using different laser powers: (a, b) $330 \mathrm{~W}$ and (c, d) $780 \mathrm{~W}-(\mathrm{a}, \mathrm{c})$ panoramic macroscopic views of LENS blocks showing qualitative surface roughness differences and (b, d) surface zoom-ins showing layer thickness differences between low and high power conditions. ${ }^{2}$

impacts compared to conventional fabrication techniques, AM technology is being referred to as the new industrial revolution. However, to meet and exceed the property standards set by traditional manufacturing techniques, especially for critical structural applications, further improvements and significant qualification studies need to be completed. Comprehensive investigations on the static, dynamic, and high-temperature properties of AM materials must be systematically performed to establish fundamental knowledge, build meaningful processing-microstructure-property relationships, and develop integrated databases for use in computational modeling and design. Manufacturers 
then need to take the next step in (I) optimizing the AM materials and techniques, and (II) developing methods to inspect their products effectively. As an example in this direction, GE signed a Joint Technology Development Agreement (JTDA) with Sigma Labs (Santa Fe, NM) to implement in-process inspection technologies, which are anticipated to improve quality and increase additive production rates by $25 \%$.

From Star Trek's "Replicator" to large manufacturing facilities and military in-the-field portable fabrication $^{51}$ to personal offices ${ }^{52}$ and the food industry, ${ }^{53} \mathrm{AM}$ is finding its way in a wide range of applications, playing the role of "mass customization." AM technology not only is used to manufacture critical components such as turbine blades, medical devices, and other complex structural parts but also is used by enterprising fabricators to produce 3D printed functional clocks, guns, robots, and even 3D printer parts (the RepRap project). An important developing trend of AM is to grow personal uses, which makes this technology even more attractive, as Wohlers ${ }^{5}$ so revealingly stated: "Now, using AM, almost anyone located almost anywhere-even in a college dormitory or spare room in a home-can become a manufacturer."

\section{ACKNOWLEDGEMENTS}

The authors thank the consortium members of the Integrative Materials Design Center (iMdc) for supporting the AM research at WPI and Benét Laboratories for providing LENS Ti-6Al-4V materials and valuable technical discussions.

\section{REFERENCES}

1. ASTM F2792-12a, Standard Terminology for Additive Manufacturing Technologies, vol. 10.04.

2. Y. Zhai and D.A. Lados, Integrative Materials Design Center (iMdc), Bi-annual Progress Report (Worcester, MA: WPI, 2012).

3. T.A. Campbell, C.B. Williams, O.S. Ivanova, and B. Garrett, Could 3D Printing Change the World? Atlantic Council. http://www.atlanticcouncil.org/publications/reports/could3d-printing-change-the-world. Accessed 10 Jan 2014.

4. Additive Manufacturing Study Shows Cuts in Material Consumption and Reduced $\mathrm{CO}_{2}$ Emissions, Powder Metall. Rev. http://www.ipmd.net/articles/002490.html. Accessed 7 Jan 2014.

5. N. Serres, D. Tidu, and S. Sankare, J. Clean. Prod. 19, 1117 (2011).

6. T. Wohlers, Manuf. Eng. 146, 70 (2011).

7. GE Asks Maker Community to Push the Boundaries of What is 3D Printable, Launching Open Engineering Quests (MarketWatch 2013). http://www.marketwatch.com/story/ ge-asks-maker-community-to-push-the-boundaries-of-whatis-3d-printable-launching-open-engineering-quests-2013-0611. Accessed 24 Feb 2014.

8. T. Wohlers, Wohlers Report 2011 (Fort Collins, CO: Wohlers Associates, 2011).

9. D.L. Bourell, J.J. Beaman, Jr., M.C. Leu, and D.W. Rosen, A Brief History of Additive Manufacturing and the 2009 Roadmap for Additive Manufacturing: Looking Back and Looking Ahead (US, Turkey Workshop on Rapid Technologies, 2009).
10. J.E. Blanther, U.S. patent 473,901 (1892).

11. O.J. Munz, U.S. patent 2,775,758 (1956).

12. W.K. Swainson, U.S. patent 4,041,476 (1977).

13. R.E. Schwerzel, V.E. Wood, V.D. McGinniss, and C.M. Verber, Proc. SPIE 90 (1984).

14. A. Ciraud, Process and Device for the Manufacture of any Objects Desired from any Meltable Material, FRG Disclosure Publication 2263777, 1972.

15. R.F. Housholder, U.S. patent 4,247,508 (1981).

16. H. Kodama, Rev. Sci. Instrum. 52, 1770 (1981).

17. A.J. Herbert, J. Appl. Photogr. Eng. 8, 185 (1982).

18. A. Lou and C. Grosvenor, Selective Laser Sintering, Birth of an Industry (Austin, University of Texas, 2012). http://www. me.utexas.edu/news/2012/0712_sls_history.php\#ch4. Accessed 22 Mar 2013.

19. Machine Solutions. http://www.concept-laser.de/en/industry/ aerospace/machines.html. Accessed 13 May 2013.

20. Laser Sintering. http://www.additive3d.com/sls.htm. Accessed 10 May 2013.

21. R.R. Mudge and N.R. Wald, Weld. J. 86, 44 (2007).

22. Direct Additive Fabrication of Metal Parts and Injection Molds. http://www.additive3d.com/tl_221a.htm\#dmds. Accessed 9 May 2013.

23. LENS Technology. http://www.optomec.com/AdditiveManufacturing-Technology/Laser-Additive-Manufacturing. Accessed 13 May 2013.

24. Laser Powder Forming. http://www.additive3d.com/lens. htm. Accessed 9 May 2013.

25. C.A. Brice and D.S. Henn (Paper presented at the International Institute of Welding Conference, Copenhagen, Denmark, 2002).

26. K.M. Taminger and R.A. Hafley, Electron Beam Freeform Fabrication for Cost Effective Near-Net Shape Manufacturing. CASI, 2006.

27. A. Fima, Directed Manufacturing, Inc., Austin, TX, private communication, April 2013.

28. Additive Manufacturing Market (2012-2017), Markets and Markets. http://www.marketsandmarkets.com/Market-Reports/ additive-manufacturing-medical-devices-market-843.html. Accessed 10 Sept 2013.

29. POM Group, Inc., Precision Additive Manufacturing of Medical Devices, White Paper (Auburn Hills, MI: The POM Group, Inc.). http://www.nist.gov/tip/wp/pswp/upload/129 precision_additive_manufacturing_of_medical_device.pdf. Accessed 10 Sept 2013.

30. Assem. Automat. Mini Feat. 31(3) (2011).

31. A.R. Thryft, Unmanned Aerial Vehicles Fly Via Additive Manufacturing. www.designnews.com/author.asp?section $i d=1386 \& d o c \_i d=235660$. Accessed 4 Jan 2012.

32. A.R. Thryft, 3D Printing Flies High. www.designnews.com/ author.asp?section_id=1392\&doc_id=251526. Accessed 17 July 2013.

33. J.L. LaGoy, MS\&T 2011 Conference Internal Bodycote Trip Report (Westerville, OH: MS\&T, 2011).

34. A.R. Thryft, Daimler Funds 3D Printer for Auto Production. www.designnews.com/author.asp?section_id=1392\&doc_id= 256731. Accessed 17 July 2013.

35. R. Brooks, Molding Concept May Speed Investment Casting. www.foundrymag.com/Classes/Article/ArticleDraw.aspx? CID $=88814 \&$ Refresh $=1$. Accessed 17 July 2013.

36. J. Strauss, HJE Company, Inc., Queensbury, NY, USA, private communication, April 2013.

37. D.L. Bourell, M.C. Leu, and D.W. Rosen (Paper presented at the Roadmap for Additive Manufacturing (RAM) Workshop, 2009).

38. R. Sreenivasan, A. Goel, and D.L. Bourell, Phys. Procedia 5, $81(2010)$

39. Additive Manufacturing Consortium. http://ewi.org/additivemanufacturing-consortium. Accessed 24 Sept 2013.

40. L.E. Murr, S.M. Gaytan, D.A. Ramirez, E. Martinez, J. Hernandez, K.N. Amato, P.W. Shindo, F.R. Medina, and R.B. Wicker, J. Mater. Sci. Technol. 28, 1 (2012).

41. R.S. Amano and P.K. Rohatgi, Mater. Sci. Eng. A 528, 6680 (2011). 
42. K. Kempen, E. Yasa, L. Thijs, J.-P. Kruth, and J. Van Humbeeck, Phys. Procedia 12A, 255 (2011).

43. L. Thijs, F. Verhaeghe, and T. Craeghs, Acta Mater. 58, 3303 (2010).

44. X. Wu, J. Liang, and J. Mei, Mater. Des. 25, 137 (2004).

45. B. Baufeld, E. Brandl, and O. van der Biest, J. Mater. Process. Technol. 211, 1146 (2011).

46. P. Ganesh, R. Kaul, and C.P. Paul, Mater. Sci. Eng. A 527, 7490 (2010).

47. E. Chlebus, B. Kuźnicka, and T. Kurzynowski, Mater. Character. 62, 488 (2011).

48. P.L. Blackwell and A. Wisbey, J. Mater. Process. Technol. 170, 268 (2005).

49. B. Vrancken, L. Thijs, and J. Kruth, J. Alloys Compd. 541, 177 (2012).
50. GE Aviation Signs Additive Manufacturing Cooperative Agreement with Sigma Labs. http://www.geaviation. com/press/other/other_20130524.html. Accessed 13 Jan 2014.

51. D.J. Hill, 3D Printing on the Frontlines-Army Developing \$2.8 M Mobile Fabrication Labs. http://singularityhub.com/ 2013/02/28/3d-printing-on-the-frontlines-army-deploying-28m-mobile-fabrication-labs/. Accessed 13 Jan 2014.

52. S. Essaid, Make Your Own Products: 3D Printing Reaches Consumers. http://techland.time.com/2013/01/15/make-yourselfinto-an-action-figure-3d-printing-reaches-consumers/. Accessed 20 Feb 2014.

53. K. Baker, Order 3D Printed Pasta at Google's Cafeterias. http://www.psfk.com/2012/08/3d-printed-pasta-google-cafeteria. html. Accessed 24 Feb 2014.

\section{APPENDIX: Additive Manufacturing Techniques, Operating Principles, and Representative Manufacturers/Equipment Vendors}

Table I. Classification of AM techniques based on input material

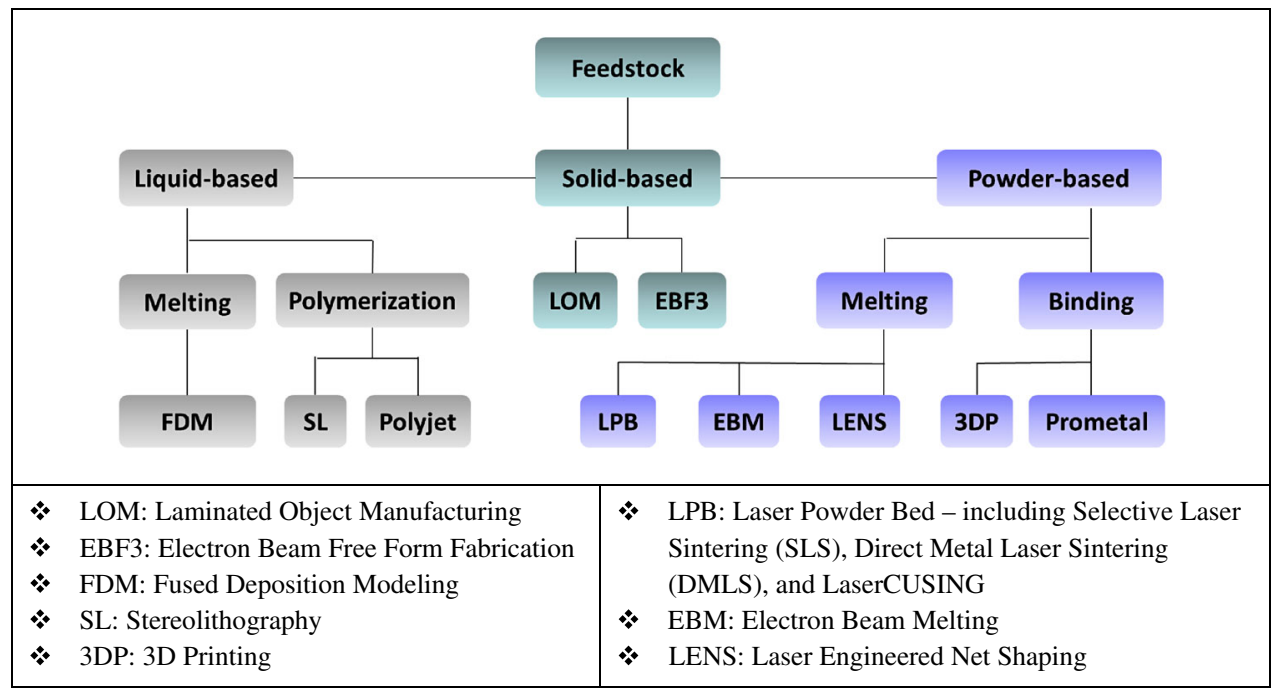

Table II. Operating principles and representative manufacturers/equipment vendors

\begin{tabular}{|c|c|c|c|}
\hline AM process & Acronym & Representative vendors & Operating principle \\
\hline $\begin{array}{l}\text { Direct metal laser sintering/ } \\
\text { selective laser melting }\end{array}$ & DMLS/SLM & EOS renishaw & Powder bed + laser beam \\
\hline LaserCUSING & LaserCUSING & Concept laser & \\
\hline Electron beam melting & EBM & Arcam AB & Powder bed + electron beam \\
\hline Laser engineered net shaping & LENS & Optomec & Metal powder (nozzle \\
\hline Direct metal deposition & DMD & $\begin{array}{c}\text { DM3D technology } \\
\text { (formerly POM group) }\end{array}$ & delivered) + laser beam \\
\hline Laser powder deposition & LPD & Huffman Corp. & \\
\hline Fused deposition modeling & FDM & Stratasys & $\begin{array}{c}\text { Filament material + laser } \\
\text { beam }\end{array}$ \\
\hline $\begin{array}{l}\text { Electron beam freeform } \\
\text { fabrication }\end{array}$ & EBF3 & Sciaky, Inc. & Metal wire + electron beam \\
\hline $3 \mathrm{D}$ printing & $3 \mathrm{DP}$ & 3D systems ExOne & Powder bed + inkjet head \\
\hline Stereolithography & SL & 3D systems & $\begin{array}{c}\text { Liquid photopolymer + UV/ } \\
\text { laser beam }\end{array}$ \\
\hline
\end{tabular}

